
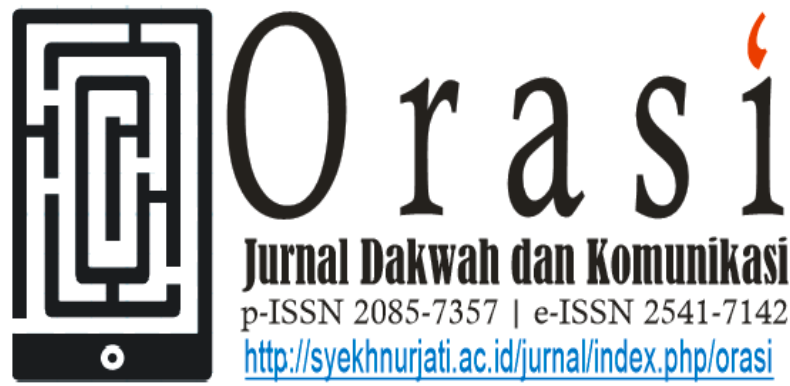

Volume 9 No. 1, PP 95 - 110; Juli 2018

\title{
PROSES VISUALISASI BUKU DONGENG TIMUN MAS DENGAN TEKNIK POP-UP UNTUK PENGEMBANGAN KEMAMPUAN KOMUNIKASI ANAK
}

\author{
Ida Nisaurrasyidah ${ }^{(*)}$ \\ Departemen Pendidikan Senirupa, \\ Fakultas Seni dan Desain, Universitas Pendidikan Indonesia \\ $\underline{\text { senoridaziggy@gmail.com }}^{(*)}$
}

\begin{abstract}
ABSTRAK
Salah satu cara yang efektif untuk mengawal tumbuh kembang pola piker, melatih otak dan meningkatkan komunikasi anak ke arah yang positif yaitu dengan mengakrabkan dan menyibukkan anak dengan belajar tanpa menghilangkan waktu bermainnya. Buku bergambar termasuk buku ringan yang dapat menghibur sekaligus mendidik anak. Buku bergambar berbentuk pop-up menjadi salah satu bentuk buku cerita yang lebih diminati anak karena tampilannya yang menarik. Tidak banyak buku bergambar pop-up yang mengangkat tema mengenai cerita nusantara di Indonesia, hal ini sangat penting karena selain ceritanya menarik di dalamnya mengandung pesan moral yang baik untuk anak, serta untuk ikut melestarikan keberadaan dongeng nusantara. Salah satu dongeng populer di Indonesia adalah Timun Mas. Timun Mas merupakan tokoh utama yang umurnya berkisar antara 9-12 tahun. Pemeran utama cerita Timun Mas berumur sama dengan target pembaca, hal ini baik sebagai contoh untuk anak-anak yang merupakan peniru ulung yang baik. Proses pembuatan buku dongeng Timun Mas menggunakan teknik pop-up melalui beberapa tahapan berkarya, proses pembuatn synopsis, proses studi karakter, tahap pembuatan storyboard, tahap pembuatan teknik pop-up, pembuatan prototype, proses pembuatan sketsa, proses pewarnaan, tahap scanning, proses penulisan teks, tahap editing, tahap printing, tahap cutting, tahap rakit, dan tahap pengemasan karya.
\end{abstract}

Kata Kunci: dongeng, Timun Mas, teknik pop-up, kemampuan komunikasi. 


\section{PENDAHULUAN}

Salah satu upaya yang efektif untuk mengawal tumbuh kembang anak ke arah yang positif yaitu dengan mengakrabkan dan menyibukkan anak dengan belajar tanpa menghilangkan waktu bermainnya. Salah satu upaya membangun dan menjaga karakter pada anak usia 9-12 tahun adalah dengan mengontrol aktivitas anak. Bila dilihat karakteristik anak pada usia ini, pada dasarnya anak usia ini memiliki perkembangan positif, antara lain yaitu senang akan hal-hal yang menantang/ baru, berpikir logis, senang membaca, dan cenderung berteman secara berkelompok. Anak mendapat hiburan dengan membaca dan dapat dijadikan sebagai sarana belajar serta memahami pesan-pesan yang terkandung di dalamnya.

Pendidikan merupakan kebutuhan pokok yang harus dipenuhi oleh setiap insan. pendidikan mempunyai peranan penting dalam menentukan arah hidup dan keberhasilan seseorang. Bercerita merupakan salah satu metode pembelajaran yang baik namun seringkali diacuhkan pada masa sekarang ini, dengan alasan tidak ada waktu, atau bahkan dengan alasan anakanak lebih sering menonton televisi dan bermain gadget. Inilah faktor utama yang menyebabkan para pendidik melupakan cara yang penting ini dan perlu mempersiapkan dan juga membentuk jati diri anak-anak. Bercerita bertujuan menumbuhkan kemampuan yang baru bagi anak. Membuka wawasan anak, melatih anak untuk pintar berkomunikasi, mengembangkan bahasa anak, mengembangkan perbendaharaan kata dan tata bahasa, serta membantu dalam persiapan untuk membaca dan menulis.

Untuk memfasilitasi perkembangan pola pikir yang positif pada anak terutama perkembangan komunikasinya, dapat digunakan media pembelajaran yang bervariasi. Media pembelajaran yang bervariasi dapat membantu anak mengembalikan semangat belajarnya, membuat anak tertarik dan tertantang untuk mengikuti proses pembelajaran tanpa membuat anak menjadi jenuh dan bosan dalam mengikuti proses pembelajaran. Media pembelajaran di antaranya yaitu buku, yang menjadi pilihan sebagai salah satu media dalam membentuk karakter anak. Dengan media buku dapat membantu guru dan orang tua dalam mendampingi perkembangan positif dari komunikasi anak, terutama buku-buku ringan. Artinya, buku yang dekat dengan dunia mereka.

Buku bergambar termasuk buku ringan yang dapat menghibur sekaligus mendidik anak. Anak mendapat kesenangan dalam membaca buku bergambar dan dapat dijadikan sarana belajar serta memahami pesan moral yang terkandung di dalamnya. 
Saat ini buku bergambar untuk anak mengalami perkembangan sangat pesat dengan berbagai jenis dan bentuknya.

Buku bergambar berbentuk pop-up menjadi salah satu bentuk buku cerita yang lebih diminati anak karena tampilannya yang menarik.

Menurut pendapat Sabuda (2014), seorang ahli paper engeenering dalam websait pribadinya mengatakan bahwa:

There are so many things competing for a young reader's attention today like television, the computer, video games, $C D$ 's, DVD's. I think a lot of parent's like pop-up books because they can educate and entertain a child but are not a part of the electronic world. You don't need to plug a pop-up book in and "boot" it up. You can enjoy it anywhere you want any time you want.

Ada begitu banyak hal yang bersaing untuk perhatian anak-anak saat ini seperti televisi, komputer, video game, CD, DVD. Sabuda berpikir banyak orang tua menyukai buku pop-up karena mereka dapat mendidik dan menghibur anak tetapi bukan dengan barang elektronik yang saat ini merajalela. Orang tua tidak perlu memasang perangkat apapun atau mengunduh dan meng-install dalam perangkat elektronik. Buku pop-up dapat dinikmati di mana saja dan kapan saja.
Buku pop-up menarik dan berbeda dari buku cerita ilustrasi biasa yang dapat memberikan kejutan-kejutan dalam setiap halamannya dan mengundang ketakjuban ketika halaman demi halaman dibuka. Unsur kejutan yang dimiliki buku pop-up dapat menumbuhkan rasa penasaran dan ingin tahu yang tinggi anak terhadap kelanjutan suatu cerita sehingga membuatnya semakin aktif. Ia juga berpendapat bahwa:

I also think, that people love the surprise of not knowing what is going to be on the next page of a pop-up book. At our studio we call that the "WOW" moment. When someone opens a pop-up book and goes "WOW!" They are really affected by the magic of a pop-up and amazed that they have the power in their hands to make it happen because they themselves are turning the pages.

Orang menyukai kejutan karena tidak mengetahui apa yang ada di dalam halaman berikutnya dari buku pop-up. Di studionya disebut dengan kata, "WOW". Ketika seseorang membuka sebuah buku pop-up dan melanjutkan ke halaman berikutnya lalu berkata, "WOW!". Mereka sangat terpengaruh oleh keajaiban pop-up dan takjub bahwa pop-up memiliki kekuatan di tangan mereka untuk 
membuatnya menjadi nyata karena mereka sendiri yang membalik halaman.

Tidak banyak buku bergambar popup yang mengangkat tema mengenai cerita nusantara di Indonesia, hal ini sangat penting karena selain ceritanya menarik di dalamnya mengandung pesan moral yang baik untuk anak, serta untuk ikut melestarikan keberadaan dongeng nusantara. Menurut Nurgiyantoro (2005) dongeng termasuk cerita rakyat lisan, yang tidak dianggap benar-benar terjadi oleh yang empunya cerita. Dongeng juga tidak terikat oleh tempat maupun waktu, karena dongeng diceritakan terutama untuk menghibur. Meskipun demikian, banyak pula dongeng yang berisi ajaran moral, melukiskan kebenaran, bahkan ada pula yang mengandung sindiran.

Salah satu dongeng populer di Indonesia adalah Timun Mas. Timun Mas merupakan tokoh utama yang umurnya berkisar antara 9-12 tahun. Pemeran utama cerita Timun Mas berumur sama dengan target pembaca, hal ini baik sebagai contoh untuk anak-anak yang merupakan peniru ulung yang baik. "Anak-anak balita, prasekolah dan mereka yang duduk di tahun-tahun pertama Sekolah Dasar adalah “peniru yang ulung”. Mereka bisa menirukan mimik muka, gerakan, sikap, bahkan kalimat-kalimat yang dilontarkan oleh orang dewasa di sekitarnya." Hardjana (2006).

Sebuah cerita mampu mempengaruhi tumbuh kembang daya khayal anak, karena menggambarkan karakter diri dari beberapa tokoh karakter. Pada dasarnya, cerita dapat membantu anak dalam mengetahui karakter yang berbedabeda dan dapat merasakannya, hal ini dapat mengaplikasikan hubungan antara anak dan karakter. Menurut DR. Sa'id Riyadh dalam bukunya yang berjudul Melatih Otak dan Komunikasi Anak, “Anak-anak usia (6-10 tahun), mereka lebih menyukai cerita-cerita mistik atau magis yang bercerita tentang orang-orang yang mempunyai kehebatan dan kekuatan khusus.".

Dongeng Timun Mas menceritakan seorang anak cerdas dan pemberani yang berjuang untuk tidak ditangkap oleh Buto Ijo yang kejam. Dalam pengejarannya, Timun Mas dibekali oleh Mbok Rondo dengan empat bungkusan kecil yang berisi biji timun, garam, jarum, dan terasi. Keempat bungkusan kecil tersebut memiliki kesaktian masing-masing guna melawan Buto Ijo. Dengan alur tersebut cerita akan menjadi lebih berkembang dan dapat membangun daya imajinasi anak yang membacanya untuk lebih kreatif.

Dilatarbelakangi oleh hal tersebut di atas, maka penulis ingin meningkatkan kemampuan otak dan juga komunikasi pada 
anak melalui media pembelajaran dengan mengangkat tema yang diambil dari dongeng nusantara Timun Emas berasal dari Jawa Tengah dibuat dalam buku cerita berbentuk pop-up book.

\section{METODE PENCIPTAAN}

\section{Pendekatan}

Penulisan ini dirancang dengan menggunakan pendekatan deskriptif. Pendekatan deskriptif adalah pendekatan yang bertujuan untuk menjelaskan kondisi yang ada, kondisi yang dapat teramati, kondisi yang terkait dengan penciptaan karya.

\section{Prosedur Penciptaan}

Gambar ilustrasi dibuat dengan warna-warna yang ceria sesuai dengan kepribadian anak. Pop-up book mampu meningkatkan kemampuan visualisasi anak. Prosedur penciptaan pembuatan karya Timun Mas (Visualisasi Dongeng Timun Mas Menggunakan Teknik Pop-Up Untuk Anak Usia 9-12 Tahun) ini di antaranya:

a) Kertas construct paper 260 gsm ukuran $21 \times 29,7 \mathrm{~cm}(\mathrm{~A} 4)$.

b) Berjumlah 16 halaman dengan 7 Pilustrasi dan cover bagian dalam.

c) Jilid hardcover.

d) Menggunakan teknik pop-up. e) Isi cerita mengunakan dwibahasa yaitu bahasa Indonesia dan bahasa Inggris.

f) Gaya pengilustrasian menggunakan gaya semi realis.

\section{Sumber Ide}

Berawal dari ketertarikan penulis terhadap film kartun produksi Disney yang menceritakan seorang putri raja. Karya ini memiliki ciri gestur tokoh yang gemulai dan gambar yang detail. Lalu timbulah keinginan untuk dibuat lebih menarik dengan ilustrasi berbentuk tiga dimensi. Dalam memilih tema cerita penulis turut serta dalam melestarikan budaya bangsa, cerita yang akan diangkat yaitu tentang cerita nusantara Timun Mas yang berasal dari Jawa Tengah.

Dongeng ini dipilih, karena jalan ceritanya sederhana yang meliputi 3 tokoh utama di dalamnya, walaupun demikian akan dibuat lebih menarik dan memiliki berbagai tujuan serta pesan moral untuk anak. Di dalamnya mengandung unsur budaya lokal yang tidak kalah menarik dari cerita luar negeri.

\section{Analisis Karya Cipta Visual}

Tema dongeng diangkat dari dongeng nusantara sederhana yang berasal dari Jawa Tengah, yaitu Timun Mas. Hal ini dikarenakan dongeng nusantara Timun Mas sangat menarik untuk dibuat pop-up book. 
Berikut adalah ringkasan cerita dongeng Timun Mas., Pada suatu hari hiduplah seorang wanita yang sangat kesepian bernama Mbok Rondo. Ia sangat menginginkan seorang anak. Ia mencari kayu bakar di hutan untuk memenuhi kebutuhan hidupnya. Suatu ketika mencari kayu bakar di hutan, ia dikejutkan oleh kemunculan Buto ijo yang licik. Buto ijo mengetahui keinginan Mbok Rondo yang sedih karena sangat menginginkan seorang anak. Dengan kelicikannya ia memberikan timun mas yang berisi seorang bayi sangat cantik untuk mengabulkan keinginan Mbok Rondo. Ia memberikan syarat kepada Mbok Rondo bahwa bayi itu hanya boleh dirawat selama sepuluh tahun. Setelah sepuluh tahun Buto ijo akan kembali mengambil Timun mas untuk dijadikan makanan. Sepuluh tahun telah berlalu Buto Ijo yang sudah tidak sabar karena ingin menyantap daging segar akhirnya pergi menjemput Timun Mas. Bumi bergetar menandakan sang Buto telah datang Timun Mas dikagetkan oleh suara jeritan Mbok Rondo yang memintanya untuk segera pergi menyelamatkan diri. Dalam Perjalanan Timun Mas berusaha untuk melarikan diri dari kejaran Sang Buto Ijo.

Timun Mas sebagai tokoh utama dibuat dengan karakter ramah, cerdas dan pemberani. Mbok Rondo sebagai tokoh pendukung protagonis berkarakter penyayang, ulet, gigih, dan berperasaan lembut. Buto Ijo dengan keadaan fisik yang tinggi, besar, mengerikan, dan tidak rupawan, tetapi masih ada sisi positifnya yaitu bersikap sabar menanti 10 tahun lamanya. Karakter para tokoh tersebut dapat membuat anak lebih semangat membaca, dan juga dapat mencontoh sikap positif serta pesan moral yang disampaikan pada buku pop-up book ini.

Dengan bekal yang telah disiapkan oleh Mbok Rondo dalam mimpinya akhirnya Timun Mas berhasil menyelamatkan diri dari kejaran Buto Ijo dan kembali hidup tenang bersama Mbok Rondo.

Gaya penggambaran buku cerita bergambar Timun Mas ini menggunakan gaya semi realis dengan pewarnaan yang ceria, hal ini dikarenakan untuk menarik perhatian anak. Narasi (teks) dalam buku pop-up ini menggunakan dwi bahasa yaitu bahasa Indonesia dan juga bahasa Inggris.

\section{Teknik dan Medium Penciptaan}

Teknik dalam pembuataan pop-up picture book ini dimulai dengan membuat storyline, kemudian ke tahapan storyboard, storyboard tersebut akan diukur ke dalam pembagian beberapa gambar dalam teknik manual pada kertas sketsa 150gram, dan dikomputerisasi menggunakan CorelDRAW X4. Setelah ukuran sudah terbentuk, tahap berikutnya adalah mencetak pola dan membuat sketsa dengan 
menggunakan teknik tracing. Selanjutnya diberi pewararnaan manual dengan menggunakan media cat poster. Tahapan berikutnya adalah proses scanning dan editing teks dengan menggunakan teknik komputerisasi Adobe Photoshop CS3 dan InDesignCS3. Ilustrasi akan dicetak pada kertas construct paper 260gsm, dilanjutkan ke proses berikutnya yaitu cutting dan juga perakitan gambar. Hasil akhir buku pop-up ini akan dijilid hardcover.

\section{HASIL DAN PEMBAHASAN}

Proses pembuatan buku dongeng Timun Mas menggunakan teknik pop-up melalui beberapa tahapan berkarya, Proses pembuatn synopsis, proses studi karakter, tahap pembuatan storyboard, tahap pembuatan teknik pop-up, pembuatan prototype, proses pembuatan sketsa, proses pewarnaan, tahap scanning, proses penulisan teks, tahap editing, tahap printing, tahap cutting, tahap rakit, dan tahap pengemasan karya.

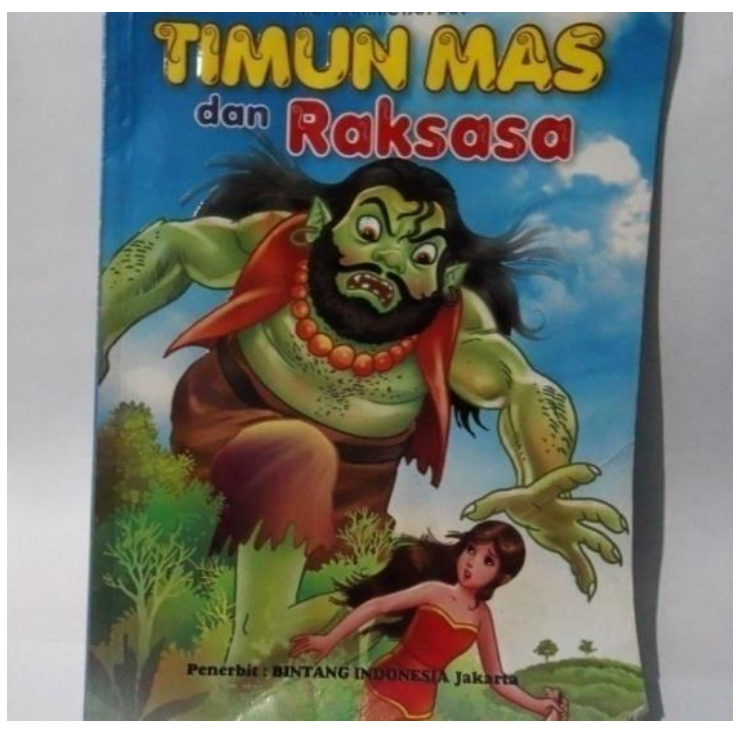

Gambar 1 Buku Dongeng Timun Mas dan

Raksasa Karya Rahimsyah

Cerita Timun Mas ini diadaptasi dari buku "Timun Mas dan Raksasa" karangan Rahimsyah (2010). Jalan cerita dibuat lebih singkat namun tetap dramatis dan mudah dipahami.

\section{Studi Karakter}

Tahapan selanjutnya adalah pembuatan studi karakter. Tahapan ini merupakan proses membuat gambar tokohtokoh yang berperan di dalam dongeng Timun Mas. Dalam tahapan ini penulis mengalami perubahan karakter tokoh berkali-kali hingga akhirnya menemukan karakter tokoh yang dirasa pas.

\section{Pembuatan Synopsis dan Naskah}




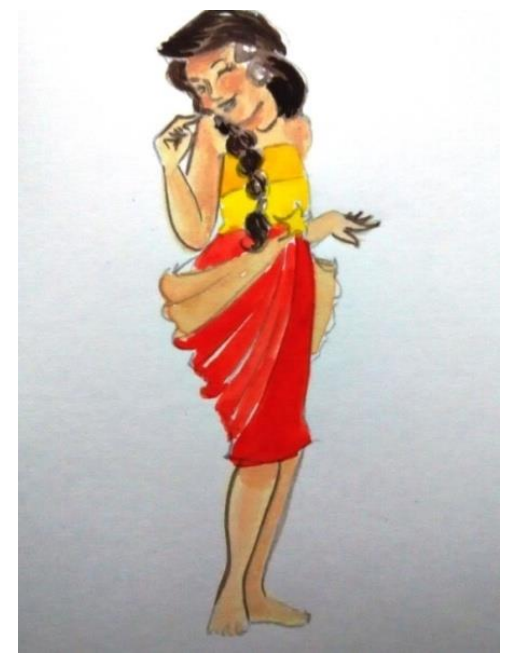

Gambar 2 karakter Timun Mas

Karakter tokoh utama Timun Mas dipilih berdasarkan perkembangan fisik anak usia 9-12 Tahun. Digambarkan sesuai dengan anak sebagai sasaran target pembaca. Dengan karakter protagonis berparas cantik, berani, optimis dan penuh semangat diharapkan dapat menjadi contoh yang baik untuk anak sebagai sasaran utama pembaca. Nama Timun Mas sendiri diambil dari buah Timun ajaib yang berwarna keemasan. Buah timun ajaib ini diperoleh Mbok Rondo dari Buto Ijo.

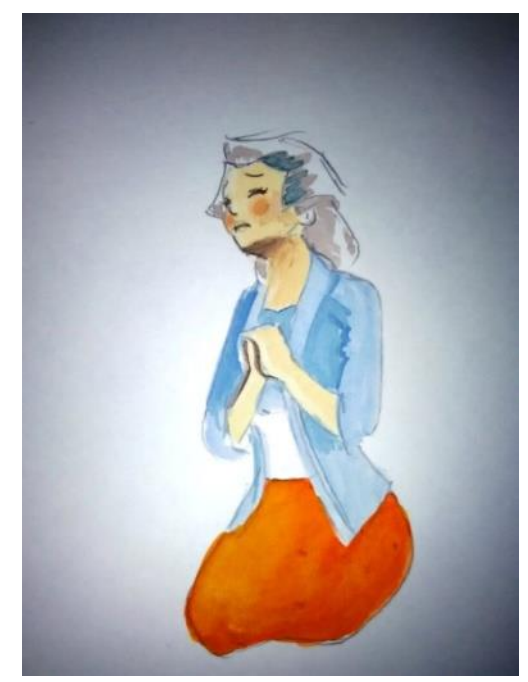

Gambar 3 karakter Mbok Rondo
Mbok Rondo merupakan seorang masyarakat sederhana biasa. Pekerjaannya mencari kayu bakar di hutan. Karakternya sebagai tokoh pendukung protagonis berkarakter lemah lembut, baik hati, rajin bekerja dan selalu berdoa. Pakaian yang dikenakan Mbok Rondo terinspirasi dari websait kebudayaanindonesia.net yang mengatakan bahwa kekhasan kebaya Jawa Tengah adalah modelnya yang merupakan model kebaya Solo atau keraton Surakarta.

Selain itu, masyarakat jawa tengah juga mengenal dua jenis kebaya yaitu kebaya pendek dan kebaya panjang. Kebaya pendek biasanya terbuat dari bahan katun polos berwarna atau brokat yang bisa juga dihiasi dengan bunga sulam. Kebaya ini juga yang biasa dipakai oleh perempuan jawa tengah sebagai busana sehari-hari.

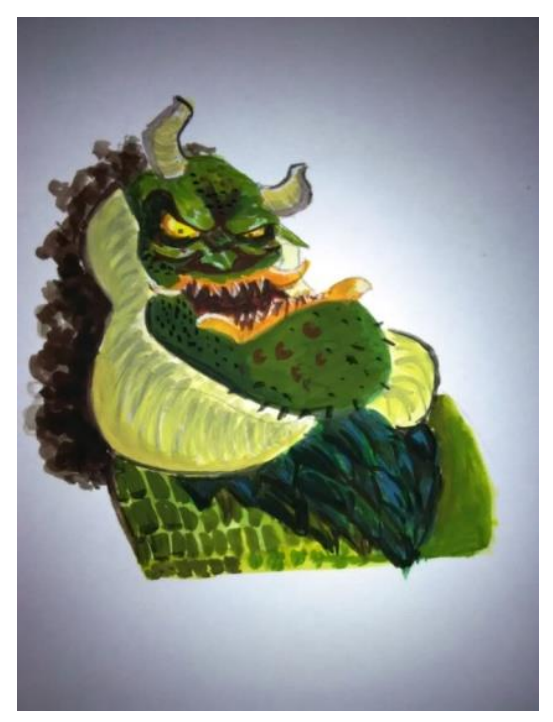

Gambar 4 karakter Buto ijo Buto Ijo berkarakter fisik tinggi, besar, mengerikan, dan tidak rupawan, 
tetapi masih ada sisi positifnya yaitu ia bersikap sabar menanti 10 tahun lamanya. Buto Ijo terinspirasi dari tokoh antagonis orc dalam film The Lord of The Ring.

\section{Pembuatan Teknik Pop-Up}

\section{Halaman 1 dan 2}

Halaman ini menceritakan tentang suasana tempat tinggal dan kegiatan Mbok Rondo sehari-hari.

Sudut pandang yang digunakan yaitu mata normal pada halaman utama dan mata burung pada halaman pelengkap. Kecenderungan warna yang akan digunakan untuk menarik perhatian anak agar mau membaca dan anak mau menceritakan kembali dengan gaya bahasanya sendiri. Warna sejuk dan hangat digunakan pada halaman ini, warna ini termasuk warna cerah. Setting cerita yang digunakan adalah lokasi wisata Dieng telaga Merdada dan Candi Sewu pada pagi hari

Halaman 1 dan 2 utama menggambarkan suasana tempat tinggal Mbok Rondo yang dibuat asimetris. Pada halaman ini gambar pop-up cenderung lebih banyak pada halaman 1 dan diseimbangkan dengan teks yang berada di halaman 2 . Komposisi teks yaitu rata justify dan jenis huruf yang digunakan adalah huruf Kristen ITC berukuran 14 .

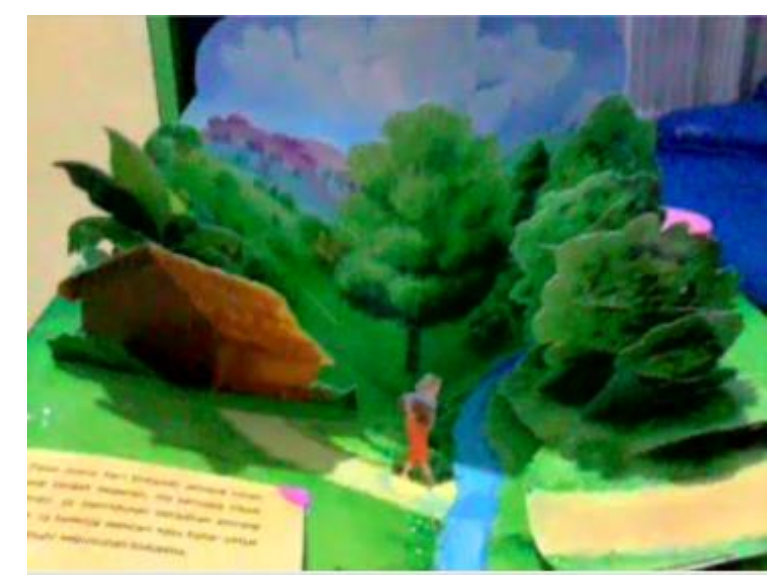

Gambar 5 Halaman 1 dan 2

Teknik pop-up yang digunakan pada halaman utama 1 dan 2adalah teknik dasar vertical vold (v-vold) pada pepohonan bagian belakang dan langit. Teknik multiplay layer pada pepohonan bagian depan dan rumah. Dan teknik lift the flap pada teks.

Halaman pelengkap 1 dan 2 terdapat dibalik teks halaman 1 dan 2. Menceritakan tentang Mbok Rondo sepulang bekerja menjadi sedih ketika melihat induk dan anak burung kepodang yang sedang bercengkrama diatas pohon. Sudut pandang yang digunakan adalah mata burung. Latar cerita di sudut hutan.

Teknik yang digunakan adalah multiple layers pada dedaunan dan teknik $v$ vold pada dedaunan yang terbuka bergerak. Jenis teks yang digunakan adalah Kristen ITC ukuran 14 dengan teks rata pada bagian pingir kanan dan kiri.

\section{Halaman 3 dan 4}




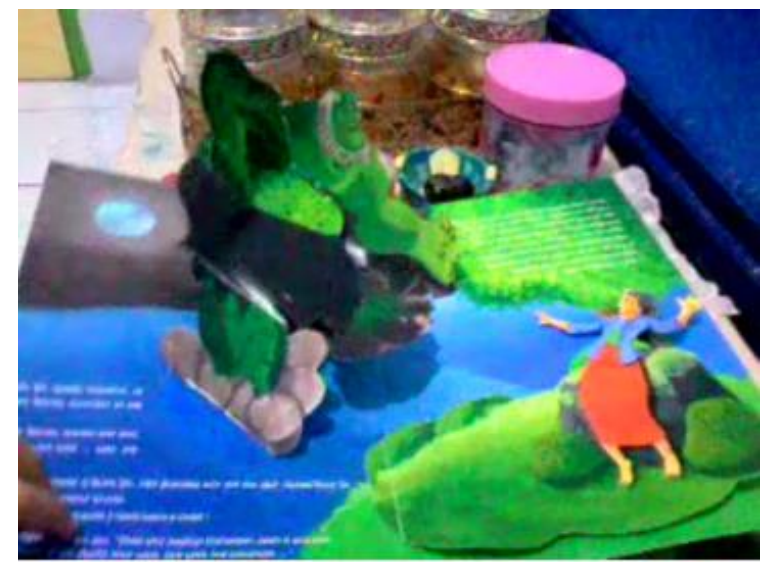

Gambar 6 Halaman Utama 3 dan 4

Halaman ini menceritakan tentang Mbok Rondo sepulang dari mencari kayu bakar dikejutkan oleh kekedatangan Buto Ijo yang secara tiba-tiba muncul dari dalam air. Buto Ijo pun mempunyai rencana jahat dengan memberi Mbok Rondo sebuah timun ajaib yang bersinar.

Sudut pandang yang digunakan adalah mata normal. Adegan ini dibuat untuk menarik minat perhatian anak agar mau membaca dan anak mau menceritakan kembali dengan gaya bahasanya sendiri. Kecenderungan warna yaitu warna sejuk pada latar dan warna hangat pada cayaha. Setting cerita berada di pegunungan Komposisi teks berada di sebelah kiri bawah. Jenis font yang digunakan yaitu Kristen ITC dengan ukuran 14.

Halaman ini dibuat asimetris dengan Buto Ijo berada di halaman 3 dan Mbok rondo berada dihalaman 4. Teknik pop-up yang digunakan adalah teknik $v$-vold pada Buto Ijo badan bagian atas dan tangan yang menghubungkan buto Ijo. Teknik multiple layer pada bagian perut dan kaki serta pada latar yang menghubungkan dengan kaki Mbok Rondo. Teknik rotary pada badan bagian atas Mbok Rondo.

\section{Halaman 5 dan 6}

Halaman ini menceritakan tentang Mbok Rondo sedang membuka buah timun ajaib berwarna emas yang bersinar ketika dibuka terdapat seorang bayi mungil nan cantik, Lalu Mbok Rondo memberi nama bayi ini Timun Mas. Namun pemberian Buto Ijo ini tidak cuma-cuma, karena Mbok Rondo harus mengembalikan Timun Mas 10 tahun kemudian kepada Buto Ijo untuk dijadikan santapannya.

Sudut pandang yang digunakan yaitu mata normal dan zoom in pada bayi Timun Mas. Warna yang digunakan adalah kombinasi warna netral, sejuk dan hangat. Komposisi teks yaitu justify pada halaman lima dan 6. Jenis font yang digunakan adalah Kristen ITC dengan ukuran font 14. Latar cerita pada malam hari. Visualisasi ini dibuat untuk menarik minat perhatian anak agar mau membaca dan anak mau menceritakan kembali dengan gaya bahasanya sendiri. 


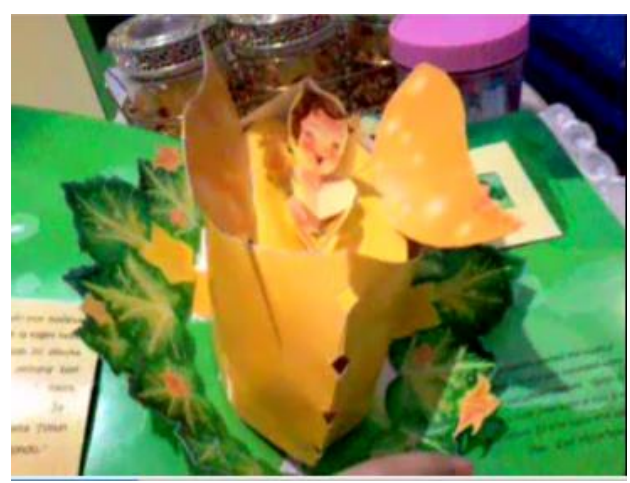

Gambar 7 Halaman 5 dan 6

Halaman ini dibuat simetris dengan buah timun dan bayi Timun Mas berada tepat dibagian di tengah. Dikelilingi hiasan bungabunga dan dedaunan tanaman timun.

\section{Halaman 7 dan 8}

Halaman 7 dan 8 menceritakan tentang petunjuk dari Tuhan dalam mimpi yang dialami oleh Mbok Rondo berubah menjadi kenyataan. Ia pun bergegas memberitahu marabahaya yang akan ditimpa oleh Timun Mas dan memberinya bekal untuk menghadapinya.

Sudut pandang yang digunakan adalah mata normal. Kecenderungan warna yaitu warna sejuk. Setting cerita berada di air terjun. Komposisi teks berada di halaman tujuh dan delapan pada bagian atas. Jenis font yang digunakan yaitu Kristen ITC dengan ukuran 14. Visualisasi ini dibuat untuk menarik minat perhatian anak agar mau membaca dan anak mau menceritakan kembali dengan gaya bahasanya sendiri.

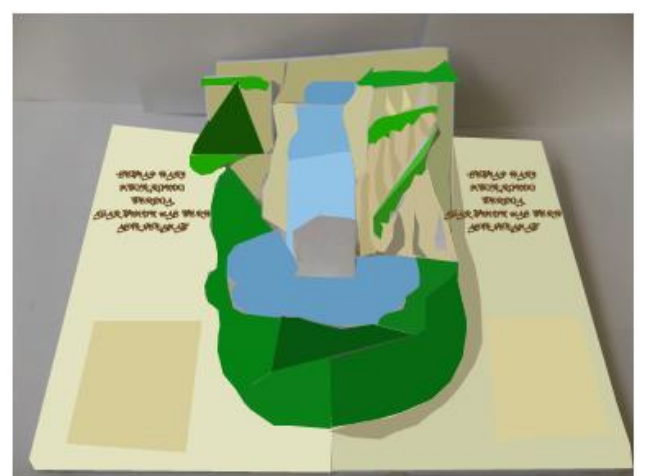

Gambar 8 Halaman 7 dan 8 Bagian 1

Halaman ini dibuat asimetris. Teknik yang digunakan bervariasi yaitu $v$ vold pada alas bawah latar dan multiple layers pada tebing. Teknik Lift the flap pada bagian bawah halaman 7 dan 8 .

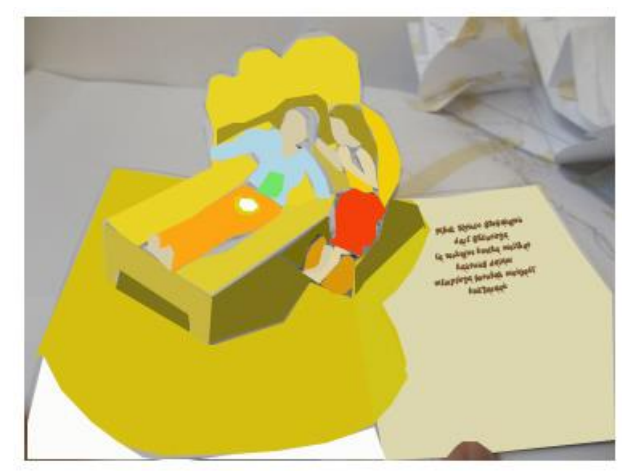

Gambar 9 Halaman 7 dan 8 Bagian 2

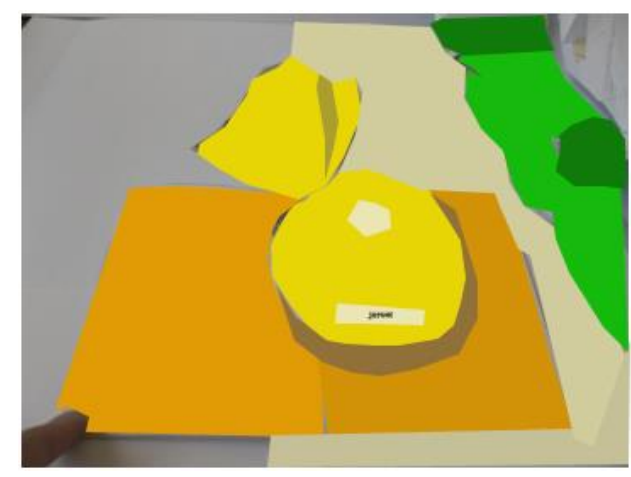

Gambar 10 Halaman 7 dan 8 Bagian 3 


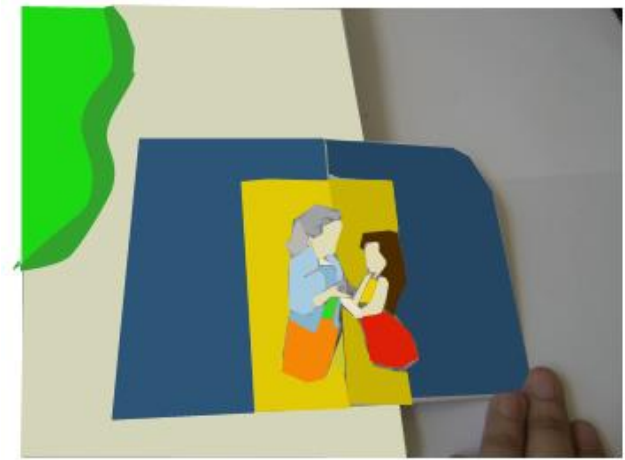

Gambar 11 Halaman 7 dan 8 Bagian 4

Bagian dalam teks halaman 7 terdapat pop-up yang menceritakan Mbok Rondo terbangun dari tidurnya. Warna yang digunakan adalah hangat. Latar cerita berada di dalam rumah Mbok Rondo. Teknik pop-up yang digunakan yaitu $v$-vold pada ranjang bambu bagian belakang. Teknik multiple layers pada ranjang bambu bagian depan dan Mbok Rondo.

Sedangkan bagian dalam teks halaman delapan terdapat pop-up yang menceritkan Mbok Rondo memberi Timun Mas bekal untuk menghadapi Buto Ijo. Warna yang digunakan perpaduan warna hangat dan sejuk. Latar cerita berada di halaman rumah. Teknik multiple layers pada Mbok Rondo dan Timun Mas. Dan teknik v-vold digunakan pada tangan Mbok Rondo. Teknik rotary pada pop-up pelengkap halaman 7 . Teknik v-vold pada pop-up halaman pelengkap. Teknik lif the flap pada teks. Teks ditulis dengan menggunakan font 12 jenis Kristen ITC.

\section{Halaman 9 dan 10}

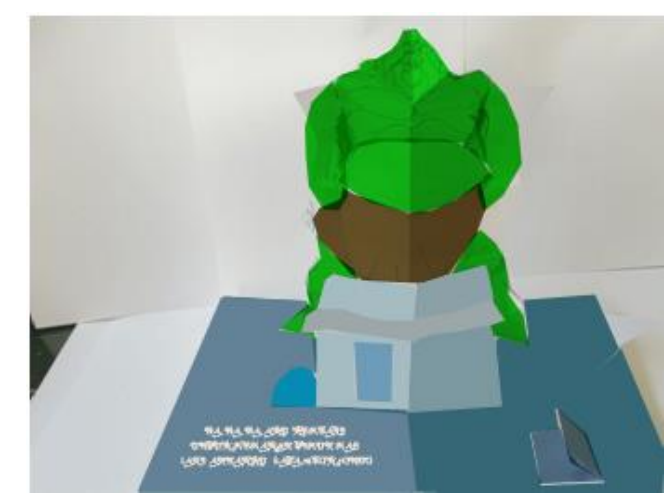

Gambar 12 Halaman 9 dan 10

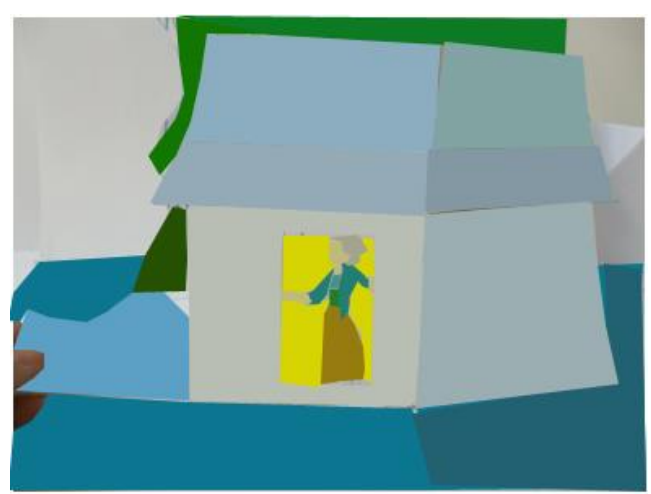

Gambar 13 Halaman 9 dan 10

Halaman ini menceritakan Buto Ijo yang datang setelah lama menunggu untuk memakan Timun Mas. Ia datang untuk mengambil Timun Mas. Timun Mas dengan sangat berani mengalihkan perhatian Buto Ijo agar Mbok Rondo dapat selamat dari amarahnya.

Sudut pandang yang digunakan adalah mata normal. Kecenderungan warna yaitu warna sejuk pada latar dan warna hangat pada cayaha. Setting cerita berada di halaman rumah Mbok Rondo. Komposisi teks menyebar pada halaman sembilan bagian bawah, di dalam pintu rumah, di badan Buto Ijo dan berada di dalam tanaman 
pada halaman 10. Jenis font yang digunakan yaitu Kristen ITC dengan ukuran 12.

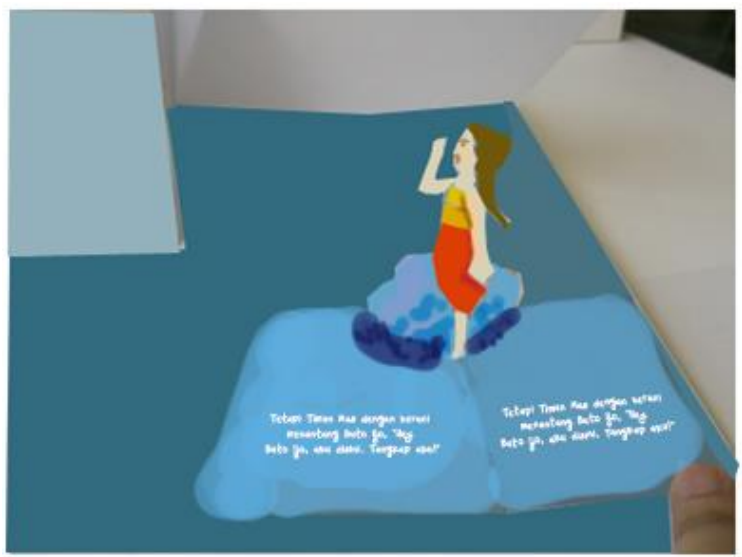

Gambar 14 Halaman 9 dan 10 Bagian 2

\section{Halaman 11 dan 12}

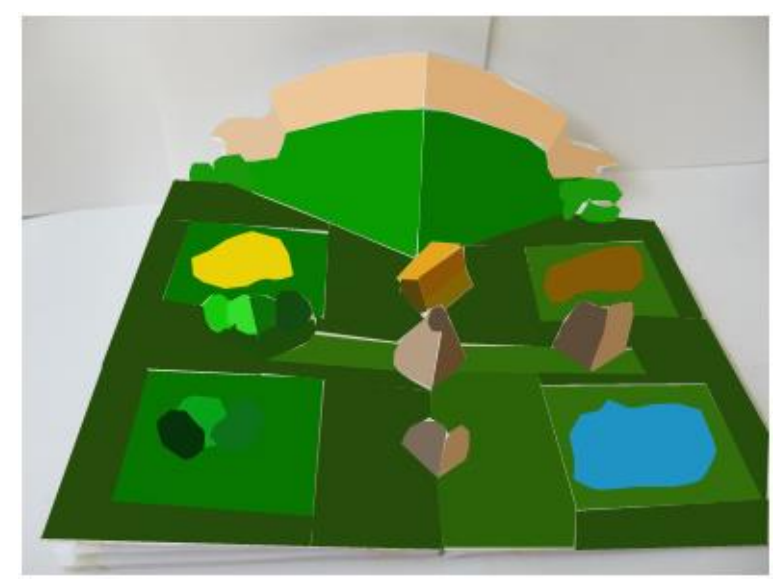

Gambar 15 Halaman 11 dan 12

Halaman ini menggambarkan tentang peta pengejaran Timun Mas yang dilakukan oleh Buto Ijo. Dibagi menjadi beberapa bagian cerita pop-up sesuai dengan bekal Timun Mas yang dilemparkan kepada Buto Ijo untuk menghambat pengejaran tersebut, yang pertama adalah biji mentimun yang berubah menjadi hamparan ladang buah mentimun. Kedua adalah bekal berisi jarum yang berubah menjadi tanaman berduri untuk melukai Buto Ijo. Ketiga yaitu bekal berisi garam yang berubah menjadi telaga untuk menenggelamkan Buto Ijo. Dan yang terakhir adalah bekal terasi berubah menjadi lumpur hidup untuk menenggelamkan Buto Ijo. Adegan ini dibuat untuk menarik minat perhatian anak agar mau membaca dan anak mau menceritakan kembali dengan gaya bahasanya sendiri.

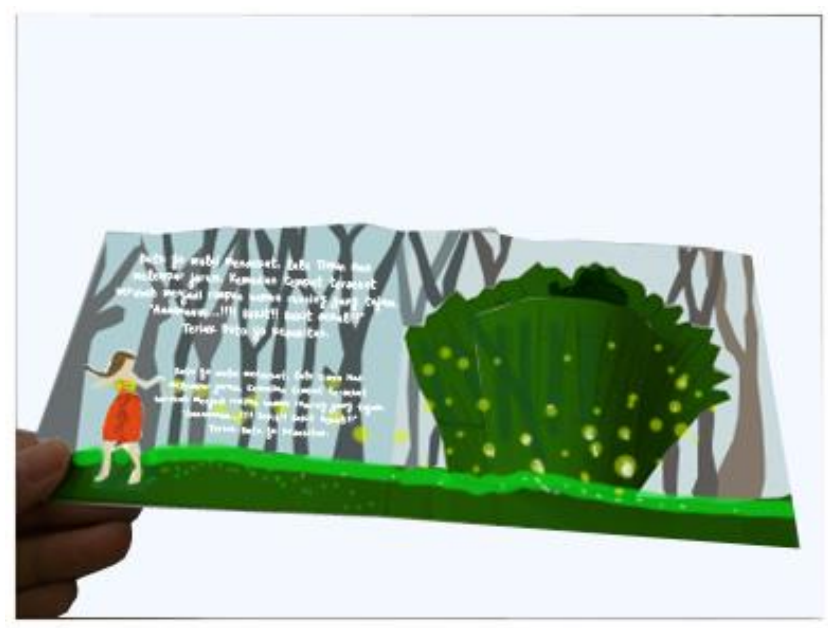

Gambar 16 Halaman 11 dan 12 Bagian 2

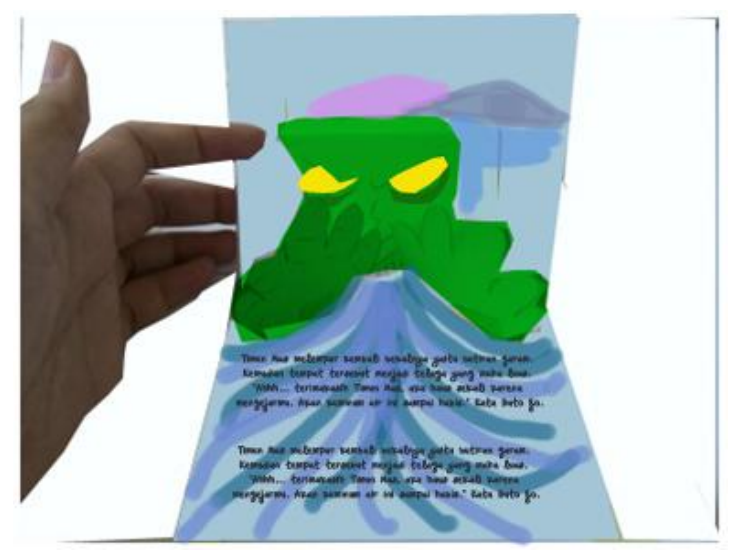

Gambar 17 Halaman 11 dan 12 Bagian 3

Sudut pandang yang digunakan yaitu mata normal. Kecenderungan warna yang digunakan adalah warna hangat. Komposisi teks berada pada bagian dalam teknik lift the flap yaitu rata tengah. Jenis font yang digunakan adalah Kristen ITC dengan 
ukuran font 12 dengan teks bahasa Indonesia berada di bagian atas teks bahasa Inggris.

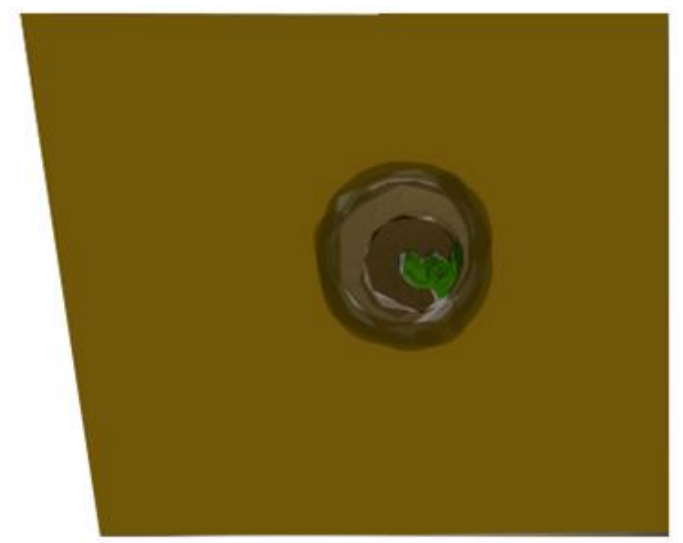

Gambar 18 Halaman 11 dan 12 Bagian 4

Teknik pop-up yang digunakan adalah extreme pop-up, dimana meliputi berbagai macam teknik dasar pop-up. Teknik wing pada bukit. Teknik lift the flap pada halaman 11 dan 12 di bagian atas dan bawah. Bagian dalam teknik lift the flap ini terdapat pop-up. Pertama, tentang Timun Mas melempar biji Timun menggunakan teknik rotary dengan gambar dapat berubah. Kedua, tentang Timun Mas melempar jarum, menggunakan teknik. Buto Ijo, Ketiga, tentang Timun Mas melempar garam, menggukanan teknik multiple layer pada bagian wajah Nuto Ijo dan v-vold pasa bagian tangan. Keempat, tentang Buto Ijo yang tenggelam didalam lumpur hidup, menggunakan teknik peek show.

\section{Halaman 13 dan 14}

Halaman ini menceritakan tentang akhir cerita dongeng Timun Mas. Ia berhasil selamat dari kejaran Buto Ijo. Ia pun kembali ke rumahnya yang disambut bahagia oleh Mbok Rondo.

Sudut pandang yang digunakan yaitu mata normal dan zoom in pada Timun Mas dan Mbok Rondo yang sedang berpelukan. Kecenderungan warna yang digunakan adalah warna hangat. Terdapat teks berisi pesan yang ditujukan kepada pembaca agar lebih berani dan tidak pantang menyerah. Komposisi teks yaitu justify pada halaman 13 dan 14, dengan teks narasi bahasa indonesia di halaman 13 dan teks bahasa Inggris di halaman 14. Jenis font yang digunakan adalah Kristen ITC dengan ukuran font 12. Visualisasi ini dibuat untuk menarik minat perhatian anak agar mau membaca dan anak mau menceritakan kembali dengan gaya bahasanya sendiri.

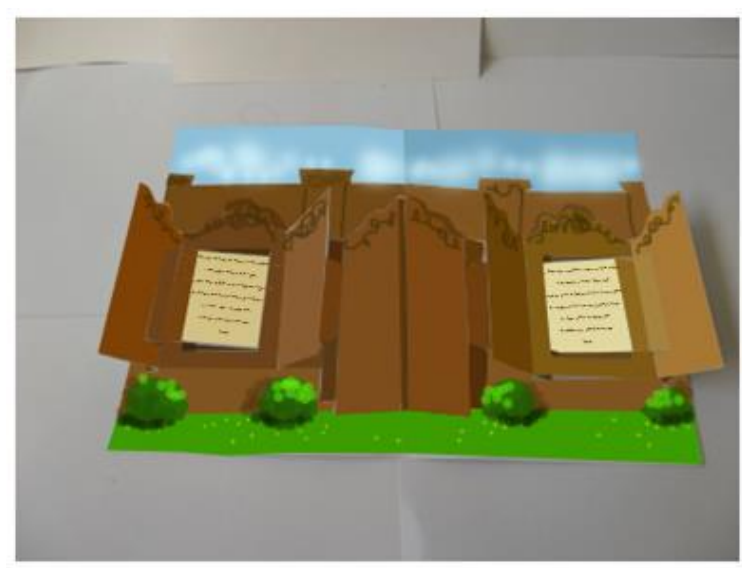

Gambar 19 Halaman 13 dan 14

Halaman ini dibuat simetris dengan frame dan pita di bagian tengah. Dikelilingi hiasan ornamen khas Jawa Tengah. 
Teknik pop-up yang digunakan adalah extreme pop-up, dimana meliputi berbagai macam teknik dasar pop-up. Teknik pop-up yang digunakan adalah dan teknik multiple layers yang divariasikan.

\section{Proses Pengemasan Karya}

Buku pop-up cenderung memiliki halaman yang tebal, untuk memudahkan dalam membuka setiap halamannya, maka buku ini akan dijilid dengan teknik hardcover agar kuat.

\section{SIMPULAN DAN SARAN}

Proses pembuatan buku dongeng Timun Mas menggunakan teknik pop-up melalui beberapa tahapan berkarya, diantaranya pembuatan sinopsis dan naskah, studi karakter, pembuatan storyline, storyboard, pembuatan teknik pop-up, pembuatan prototype, pembuatan sketsa, pewarnaan, pemindaian gambar (scanning), pengubahan teks (editing), penulisan teks, pencetakan pola gambar, pemotongan pola gambar (cutting), perakitan pola gambar, dan pengemasan karya. Teknik pembuatan yang digunakan merupakan keahlian seorang paper engineering tingkat tinggi yang terdiri dari extreme pop-up, vertical vold, diagonal box, multiplay layers, spiral, lift the flap, floating layers, pull tab, twirl, waterfall, dan peek show. Kombinasi anatara teknik yang satu dengan yang lainnya merupakan langkah inovatif agar buku dongeng Timun Mas menjadi suatu karya yang menarik dan layak untuk dinikmati.

Buku dongeng Timun Mas dengan teknik pop-up ini diharapkan menjadi contoh inovatif untuk mengembangkan media pembelajaran dalam menarik minat baca anak dan meningkatkan kecerdasan otak serta memotivasi anak untuk berkomunikasi dengan baik. Dengan tema cerita dongeng nusantara diharapkan dapat mengenalkan kekayaan budaya nusantara pada generasigenerasi penerus bangsa dalam rangka melestarikannya. Dalam konteks isi cerita diharapkan menjadi contoh sauri tauladan bagi para peniru ulung cilik yang akan menjadi penggerak bangsa di masa mendatang.

\section{DAFTAR PUSTAKA}

Capodagli-Jackson, Bill- Lynn. 2002. “ The Disney Way”. Jakarta: Erlangga.

Hardjana. (2006). “Cara Mudah Mengarang Cerita Anak-Anak". Jakarta: Grasindo.

Nurgiyantoro, Burhan. (2005). "Sastra Anak: Pengantar Pemahaman Dunia Anak".'Yogyakarta: Universitas Gadjah Mada.

Rahimsyah, A.R. (2010). "Timun Mas dan Raksasa". Jakarta: Bintang Indonesia

Riyadh, DR. Sa'id. (2011). "Melatih Otak dan Komunikasi Anak". Jakarta: Akbar Media.

Sabuda, R. (2014). "Pop-Up Question". Robert Sabuda [Online]. Tersedia: http://wp.robertsabuda.com/pop-upquestions/ . [ Januari 2014]. 
Strizver, Ilene. "Typografy for

Children". Fonts [Online]. Tersedia: http://www.fonts.com/content/learning/f yti/situational-typography/ typographyfor-children.

Susanto, Mike. 2002. "Diksi Rupa:

Kumpulan Istilah Seni Rupa".

Yogyakarta: Kanisius. 